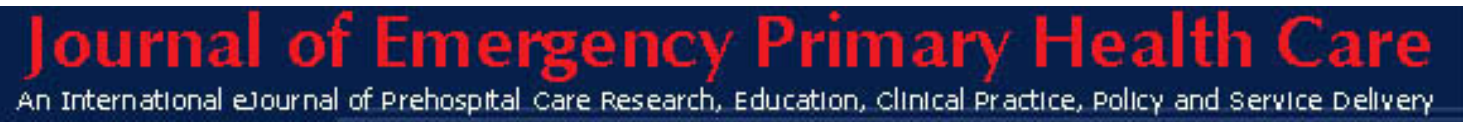

ISSN 1447-4999

\title{
EDUCATION
}

Article 990157

\section{Training for Emergency Care Practitioners: BSc Degree}

\section{Peter Gregory}

Senior Lecturer in Paramedic Practice, Coventry University, UK.

Demands for ambulance services rose by nearly $50 \%$ in the ten years from $1989,{ }^{1}$ which catalyzed a rethink in the way ambulance services delivered their care. In November 1999, the Ambulance Service Association (ASA) ${ }^{2}$ outlined possible models for future ambulance services, and included a model that would see ambulance services providing a wide range of community health care services through the development of practitioners in emergency care (PEC). This concept was supported by the Joint Royal Colleges Ambulance Liaison Committee (JRCALC) ${ }^{3}$ who advocated the development of PEC's and foresaw the movement of ambulance education towards Higher Education Institutions (HEI). Subsequent papers ${ }^{4,5}$ acknowledged the requirement to change the way ambulance services worked and recognised the need to develop the education and role of the paramedic. Other catalysts included the four hour A\&E waiting targets and reforms in out-of-hours care set out in the NHS plan, ${ }^{6}$ and the conclusions from the Carson report, ${ }^{7}$ which advocated that all those involved in the delivery of out-of-hours care should work collaboratively, and that the NHS should be striving to ensure the appropriateness of response to a call.

The Emergency Care Practitioner (ECP) role was seen by the Ambulance Service Association as a way of breaking down professional boundaries and improving the skill level of paramedics, which in turn would lead to new, collaborative ways of working and improve patient care. ${ }^{2}$ It aimed to provide patients with the most appropriate care in the most appropriate place, reduce $A \& E$ attendances and therefore improve $A \& E$ waiting times, and provide paramedics with scope for developing their careers outside the ambulance service. ${ }^{8}$ Cynically it could also be seen as a cheap way of providing out-of-hours cover for general practitioners.

In May 2002, the Emergency Care pilot, based in Coventry and Warwickshire health community, commenced. Six post registration students were recruited to help determine the competencies required for this new role - three were experienced paramedics and three were experienced A\&E nurses. The 50:50 split of nurses and paramedics aimed to ensure that the expertise of the two professions could be shared.

The education for the pilot group was provided by Coventry University, who tailored the initial part of the course to the requirements of the individual students based upon their background. The nurses undertook the Institute of Health and Care Development (IHCD) paramedic course and the IHCD driver training course; the paramedics undertook an Accident and Emergency course similar to the old ENB199, and placements in Accident and Emergency departments. Those that came without prior higher education experience also completed a study skills module at level 2, which served to support them with academic work and provided them with the level 2 study necessary to access level 3 modules. All students then followed a common programme of level 3 modules: 
- Care and management of minor injury

- Care and management of minor illness

- Autonomous emergency practice (theory component)

- Emergency practice (practice component)

- Research and statistics

- A ten thousand word dissertation

The subsequent 15-week ECP course was developed by the Changing Workforce Programme (CWP) based upon the competencies identified by the students of the pilot group but without educational input from Coventry University. The short duration of the course was similar in nature to the intensive ambulance technician and paramedic courses, based very much upon clinical competencies. As with other generalist health professionals, the potential scope of practice for the ECP is vast and with this comes the need for extensive underpinning knowledge. If the aim is for ECP is to manage presenting problems without referral then it remains to be seen whether the 15 week programme adequately prepares practitioners for the increasing clinical specifics they will need, or the anticipated exponential rises in guidelines already witnessed in General Practice. ${ }^{9}$

In the Coventry and Warwickshire area, Coventry University retook control of the local ECP programme and extended the timescale in an attempt to enhance the underpinning education and consolidation time. The minimum period for completion is now 30 weeks and, depending upon the number of modules a student completes, will lead to either a higher education diploma at level 3, or a full honours degree. Both the university and Coventry and Warwickshire Ambulance Service hypothesised that the degree route would provide students with a sound academic basis from which to make sustainable decisions, develop research skills to support evidence based practice, ensure credibility and recognition from other clinicians, and facilitate student progression to higher levels of education and training. It also sat well with the Career Framework for the NHS, ${ }^{10}$ which places first registration practitioners at level 5 with either a foundation degree or diploma, and senior/specialist practitioners (in this case the ECP) at level 6 with an honours degree. Recent documentation from the British Paramedic Association ${ }^{11}$ supports this view.

The major problem with the current variance in ECP education and service delivery is that it is neither possible to define an ECP nor establish their level of education or skill base.

Evaluation of the work of ECP's in the Coventry and Warwickshire health economy is ongoing but early information suggests a significant reduction in the number of patients being transported to A\&E departments. Cost models suggest that savings of up to $£ 72,000$ could be made per annum per $\mathrm{ECP}^{8}$ but this has yet to be demonstrated. The research underpinning the continuing development of the ECP role is sparse with no published research evaluating patient satisfaction, no published cost analyses, and no evaluation of the merits or otherwise of the educational pathways taken. It cannot be presumed that practitioners with academic backgrounds will inevitably enhance patient care and satisfaction, which makes it essential to undertake comparative analysis of the differing academic pathways to ECP qualification.

The blurring of professional boundaries has been aided by the inclusion of nurses in the Coventry and Warwickshire ECP programme. Currently 23 nurses and 31 paramedics have either completed the programme or are in the process of completing their studies. Blurring boundaries is potentially easier if practitioners from both sides of the dividing line are included in the developments but inclusion of nurses has not been a significant feature of many of the ECP programmes. 
There remains a need to evaluate the ECP programmes currently being delivered across the Country in terms of clinical outcome, patient satisfaction and cost-effectiveness, and it is of paramount importance that a national strategy be agreed and implemented based upon the findings. It is neither possible to define an ECP nor establish their level of education or skill base - this must change so that the transferability of skills inherent in the aims of the CWP can be realised.

\section{References}

1. Department of Health. Statistical bulletin 2000/14: ambulance services, England: 1999-2000. London: DOH, 2000.

2. Ambulance Service Association. The Future of Ambulance Services in the United Kingdom. London: Ambulance Service Association, 1999.

3. Joint Royal Colleges Ambulance Liaison Committee and The Ambulance Service Association. The future role and education of paramedic ambulance personnel (emerging concepts), Joint Royal Colleges Ambulance Liaison Committee, 2000.

4. Department of Health. Reforming emergency care. London: Department of Health, 2000.

5. Department of Health. A health service for all the talents: developing the NHS workforce. Consultation document on the review of workforce planning. London: Department of Health, 2000.

6. Department of Health. The NHS Plan: A plan for investment, a plan for reform. London: Department of Health, 2000.

7. Department of Health. Raising standards for patients: new partnerships in out-ofhours care. London: Department of Health, 2000.

8. Department of Health. Right Skill, Right Time, Right Place. The ECP Report. London: Department of Health, 2004.

9. Hibble A, Kanka D, Pencheon D, Pooles F (1998) Guidelines in general practice: the new Tower of Babel? BMJ 1998;317;862-863.

10. Department of Health. A career framework for the NHS, London: Department of Health, 2005.

11. British Paramedic Association. A Curriculum Framework for the Ambulance Profession, consultation document. Derby: British Paramedic Association, 2005.

\section{Author Disclosure}

The author has no financial, personal or honorary affiliations with any commercial organization directly involved or discussed in this study.

This Article was peer reviewed for the Journal of Emergency Primary Health Care Vol.4, Issue 1, 2006 